\title{
ПРИМЕНЕНИЕ AR-TЕХНОЛОГИЙ В ДЕЯТЕЛЬНОСТИ КАДАСТРОВОГО ИНЖЕНЕРА
}

\author{
Любовь Александровна Максименко \\ Сибирский государственный университет геосистем и технологий, 630108, Россия, г. Новоси- \\ бирск, ул. Плахотного, 10, кандидат технических наук, доцент кафедры геоматики и инфра- \\ структуры недвижимости, тел. (383)361-07-09, e-mail: maksimenko_la@mail.ru
}

Дополненная реальность создает эффект восприятия информации, возникающий при взаимодействии человека с устройством, дополняющим физический мир цифровыми данными. B статье рассматриваются вопросы применения AR-технологий для кадастровых инженеров, деятельность которых происходит в динамично развивающемся информационном поле объектов недвижимости. Приведен пример разработки пилотного проекта «AR в деятельности кадастрового инженера», выполненный на платформе ARGUMENT. Показано, что приложения дополненной реальности, разработанные для мобильных устройств, способствуют формированию нового направления работы с информацией.

Ключевые слова: Технология дополненной реальности, цифровые технологии, кадастровый инженер, объект недвижимости, мобильные устройства, информация, эффект восприятия информации

\section{APPLICATION OF AR-TECHNOLOGIES IN THE ACTIVITIES OF A CADASTRAL ENGINEER}

\section{Ljubov A. Maksimenko}

Siberian State University of Geosystems and Technologies, 10, Plakhotnogo St., Novosibirsk, 630108, Russia, Ph. D., Associate Professor, Department of Geomatics and Real Estate Infrastructure, phone: (383)361-07-09, e-mail: maksimenko_la@mail.ru

Augmented reality creates the effect of information perception that occurs when a person interacts with a device that complements the physical world with digital data. The article deals with the application of AR technologies for cadastral engineers, whose activities take place in the dynamically developing information field of real estate objects. An example of the development of a pilot project "AR in the activities of a cadastral engineer", performed on the ARGUMENT platform. It is shown that augmented reality applications developed for mobile devices contribute to the formation of a new direction of working with information.

Keywords: augmented reality Technology, digital technologies, cadastral engineer, real estate object, mobile devices, information, information perception effect

\section{Введение}

Технология дополненной реальности, открывает новые возможности в каждой конкретной производственной сфере. Технология дополненной реальности - это воспринимаемая реальность, созданная с использованием «дополненных», с помощью цифровых технологий, элементов воспринимаемой реальности. ARтехнологии позволяют из огромного количества информации, выделить 
главное. Используются данные технологии по-разному. В настоящее время уже накоплен большой опыт эффективного использования AR-технологий в рекламной сфере. Разрабатываются комплексные проекты продвижения новых товаров и услуг в промышленной, образовательной и социальной сферах жизни общества. Рассматриваются вопросы применения AR-технологии в BIM проектировании. Наблюдается устойчивая тенденция применения технологий «дополненной реальности» в учебном процессе [1].

Цифровая трансформация образовательной среды определена в целях и задачах федерального проекта «Цифровая образовательная среда» национального проекта «Образование». Дорожная карта развития «сквозной» цифровой технологии «Технологии виртуальной и дополненной реальности» разработана и утверждена в 2019 г. [2]. Также утвержден перечень технологий, в отношении которых будет действовать особое правовое регулирование, для ускорения развития и продвижения перспективных идей. В перечень вошли, в том числе и технологии виртуальной и дополненной реальности [3].

\section{Методы и материалы}

Рассматривая AR-технологии в деятельности кадастрового инженера, возникают вопросы: как и для чего мы это будем использовать, зачем нужны альтернативные источники информации, если есть интернет? Определяющим фактором, указывающим на применение новых решений в профессиональной деятельности, служит увеличение информационной нагрузки на специалиста, вследствие чего появляется необходимость систематизации поступающей информации. Немаловажным фактором служит периодически обновляющееся информационно-правовое поле для обеспечения планирования, организации, мониторинга и контроля кадастровых работ.

Дополненная реальность, значительно расширяет возможности систематизации материалов, изменяет традиционную функциональность мобильных устройств, привлекает неожиданными решениями интерактивных инсталляций.

Разработка проекта «AR в деятельности кадастрового инженера» была выполнена на платформе ARGUMENT [4]. Инструментарий данной платформы дает пользователям разнообразные возможности представления материалов. Разработка проекта состояла из нескольких этапов: формирование общей концепции; подготовка, анализ и оценка контента; разработка проекта на платформе; тестирование, доработка и поддержка проекта.

Для формирования AR-контента была выбрана актуальная информация, для действующих кадастровых инженеров и обучающихся по направлению «Землеустройство и кадастры», касающаяся получения дополнительного образования, информации о школе кадастровых инженеров, видеоматериалов, лекций, нормативной литературы и других материалов, что представлено на рис. 1 [5-7]. 


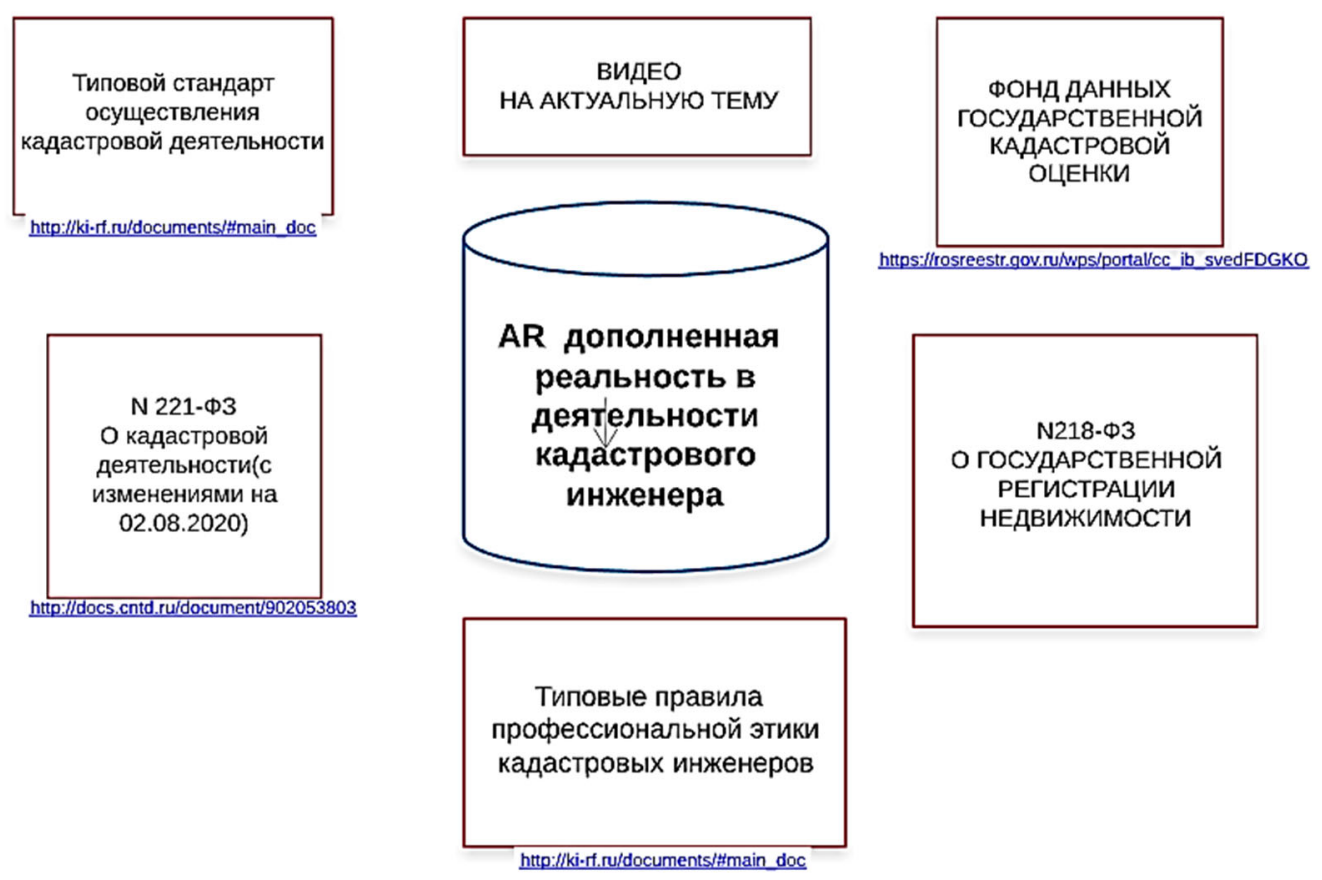

Рис. 1. Формирование контента

На рис. 2 представлен фрагмент разработанного проекта «AR в деятельности кадастрового инженера». Проект оформлен в виде листа (листовки) формата A4 в электронном виде, твердая копия проекта может быть представлена на формате A5 или в виде брошюры. Последовательность просмотра контента заключается в следующем. После предварительного скачивания платформы Argument по ссылке: https://argument.digital/ на мобильное устройство, необходимо войти в систему, путем скачивания QR-кода (см рисунок 2). Дальнейшее последовательное сканирование маркеров открывает «дополненную реальность».

\section{Обсуждение}

Проект «AR в деятельности кадастрового инженера» для мобильных устройств открывается путем сканирования QR-кода (см рисунок 2). После работы с контентом, предусмотрена возможность внесения оценки и комментариев.

\section{Заключение}

Тенденции применения мобильных устройств в профессиональной и образовательной деятельности с каждым годом проявляются все отчётливее. Представленный в данной статье пилотный проект «AR в деятельности кадастрового инженера» не только демонстрирует возможности использования AR-технологий, но и надеемся, будет способствовать привлечению специалистов и преподавателей к созданию тематических проектов для мобильных устройств, в разных областях профессиональной деятельности. 


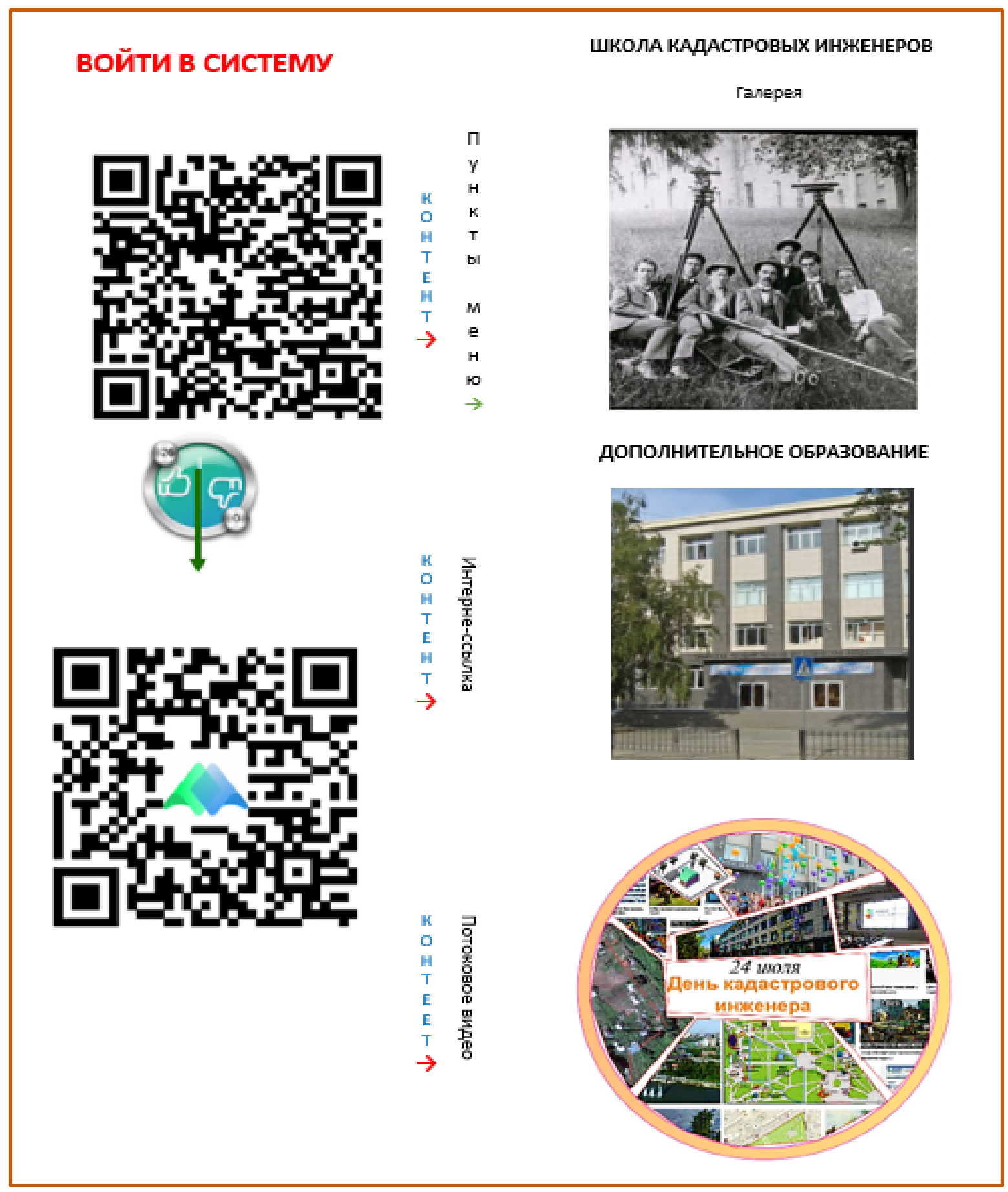

Рис. 2. Фрагмент проекта «AR-технологии в деятельности кадастрового инженера»

\section{БИБЛИОГРАФИЧЕСКИЙ СПИСОК}

1. Кислова О. Н «Дополненная реальность» сквозь призму интернет-практик современного студенчества / Кислова Ольга Николаевна // Методологія, теорія та практика соціологічного аналізу сучасного суспільства. Збірник наукових праць. -Харків видавничий центр Харківського національного університету імені В. Н. Каразіна, 2014. С.351- 356.

2. Распоряжение Минпросвещения России от 18.05.2020 N P-44 "Об утверждении методических рекомендаций для внедрения в основные общеобразовательные программы современных цифровых технологий". 
3. Постановление Правительства РФ от 28 октября 2020 г. № 1750 "Об утверждении перечня технологий, применяемых в рамках экспериментальных правовых режимов в сфере цифровых инноваций".

4. https://argument.digital/ ARGUMENT. Платформа дополненной реальности.

5. http://ki-rf.ru/ «Национальное объединение саморегулируемых организаций кадастровых инженеров».

6. https://sgugit.ru/additional-educations/ Дополнительное профессиональное образование в СГУГиТ.

7. https://rosreestronline.ru/ Сведения из Федеральной службы Государственной Регистрации Кадастра и Картографии Российской Федерации.

(C) Л. А. Максименко, 2021 